\title{
Transient and stepwise ocean oxygenation during the Ediacaran Shuram Excursion
}

\author{
ZIHENG Li ${ }^{*}$, MENGCHUN CAO ${ }^{2}$, SEAN J. LOYD ${ }^{3}$, \\ THOMAS J. ALGEO ${ }^{1,4,5}$,XIANGDONG WANG ${ }^{1 *}$, LAISHI \\ $\mathrm{ZHAO}^{1 *}$ \\ ${ }^{1}$ State Key Laboratory of GPMR, China University of Geosciences \\ ${ }^{2}$ School of Geosciences, China University of Petroleum, Qingdao \\ ${ }^{3}$ Department of Geological Sciences CSU, Fullerton \\ ${ }^{4}$ State Key Laboratory of BEG, China University of Geosciences \\ ${ }^{5}$ Department of Geology, University of Cincinnati \\ *Corresponding authors: zihengli@.cug.edu.cn
}

The Ediacaran Shuram Excursion (SE) was a key episode in the history of atmospheric and oceanic oxygenation that has also been linked to contemporaneous bio-evolutionary events. However, key aspects of the redox state of Ediacaran oceans during the SE remain unknown. Here, marine-carbonate-associated uranium isotope compositions $\left(\delta^{238} \mathrm{U}\right)$ were used to investigate shallow-water oxygenation during the SE. We found that the onset of the SE was characterized by a shift toward higher $\delta^{238} \mathrm{U}$ values, which is present in widely separated coeval sections, including in South China (from $-0.8 \%$ o to $-0.3 \%$ ), Siberia (from $-0.75 \%$ o to $-0.3 \%$ ), California (from $-0.75 \%$ o to $-0.3 \%$ ), and Mexico (from $-0.7 \%$ o to $-0.3 \%$ ). Our $\delta^{238} U$ record, in combination with published magnetostratigraphic and astrochronological data, reveals a distinct and transient oceanic oxygenation event that lasted $\sim 6.8$-Myr. The $\delta^{238} \mathrm{U}$ signal exhibits a $\sim 0.65$-Myr lag relative to the Shuram $\delta^{13} \mathrm{C}_{\text {carb }}$ excursion owing to a two-step oxygenation event during the onset of the Shuram Excursion.

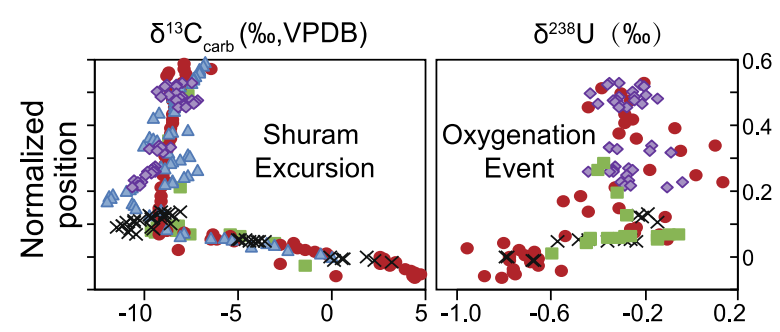

Fig. 1. $\delta^{13} \mathrm{C}_{\text {carb }}$ and $\delta^{238} \mathrm{U}$ profiles of the onset of the SE. 